\title{
HISTORY OF THE LIVERPOOL SCHOOL OF TROPICAL MEDICINE
}

\section{B. G. MAEGRAITH}

I AM often asked why there should be a tropical school in Liverpool and whether there is a place for such a school in the modern developing world. The simplest way of answering these questions is to sketch the history of the school. In my view history includes the present as well as the past and in this case should deal with the philosophy of the school as well as the people who have served in it. I shall attempt to deal superficially with the history of the Liverpool School in this way.

The first question is-Why have a tropical school in Liverpool? The factual answer is, of course, that the school was founded in Liverpool. The first of its kind in the world, it was started at the height of the Colonial Empire, when streams of doctors were going from England to the tropical colonial empire to practise clinical medicine and to deal with indigenous problems of public health. (I separate clinical medicine and health at this stage because this was the unfortunate habit in colonial administration.) At the time the school was created the British Empire needed large numbers of doctors skilled in the specific disciplines of the tropics, but had not provided any central facilities for training them.

It was not until 1898 that the British Government realized for the first time that it was sending untrained doctors to work in the colonies. There was no place in Britain which was dedicated to the necessary disciplines and there was no specific reference to them included in the medical curriculum, apart from the elementary parasitology. Moreover, there were no opportunities offered for refresher courses for those returning on leave. Doctors who went to tropical colonies had to learn the hard way by long experience. This reduced their immediate efficiency and generally lowered the standard of their work. Pressed by Manson, who had become Medical Adviser to the Colonial Office, Joseph Chamberlain, then Secretary of State for the Colonial Office, wrote a letter to the General Medical Council and to the main medical schools suggesting that adequate emphasis should be given in the ordinary medical curriculum to tropical medicine and related subjects, in order to help the many doctors who would subsequently go overseas. The G.M.C. replied, as might be expected, that it agreed in principle with the need for such training but no action was forthcoming, as the medical schools clearly considered there was no need to change existing teaching programmes for the sake of a relatively small minority who would eventually learn their tropical medicine in the tropics.

Chamberlain then addressed a letter to the Governors of all Colonies, pointing out the great mortality and morbidity arising from endemic tropical diseases such 


\section{History of the Liverpool School of Tropical Medicine}

as malaria, and the importance of the study of such diseases and the specific education of Colonial Office doctors. As the overtures to the profession regarding undergraduate teaching were unsuccessful, he proposed that specific training schools should be set up in Britain to deal with the systematic training of the Colonial Office doctors. Behind this letter was the intention, again stimulated by Manson, to start a school of training in London, based on the Seamen's Hospital, Albert Dock, Greenwich. This school was opened in October 1899, and began teaching immediately. A quite unexpected result of Chamberlain's letter was the formation of the Liverpool School, which was founded in November 1898 immediately after Chamberlain's appeal. The school was opened in April 1899, that is, some six months before the London School.

The idea of the Liverpool School apparently began at the annual dinner of students of the Royal Southern Hospital. Over the cigars there was a whispered conversation between the President of the Hospital (Adamson), Dr. Carter, who had referred in his speech to Chamberlain's appeal and Alfred Lewis Jones, head of the Elder Dempster Shipping Line. Mr. Jones then announced that he had offered $£ 350$ per annum for three years for the promotion of the study of tropical disease. This 'liberal offer', as it was called at the time, was warmly accepted by the President of the hospital. In a letter to Jones he suggested that the Royal Southern Hospital should act as the clinical focus of the studies in view of its proximity to the docks. He welcomed the collection of cases in the hospital into one centre rather than leaving them scattered about in the general wards 'as they are at present'. The postscript to this letter would be worth following up: 'PS-if my memory serves me correctly the government subsidised a number of beds in the Royal Southern Hospital for the use of soldiers returned from the Ashanti War'.

In November 1898 a committee was formed, with Jones as Chairman and Adamson representing the Hospital. Other members were Glazebrooke, Principal of the University College, surgeons and physicians of the hospital and Rubert Boyce, Holt Professor of Pathology, who became the school's first Dean. The professional members of this committee were asked to meet and plan the new school. This they did and in due course the committee communicated its intention to the Colonial Office. The reply came from Lord Ampthill and is worth quoting:

\footnotetext{
December 1st $1898 \ldots$

Mr. Chamberlain was much interested and very glad to hear of the important work you have commenced.

You are no doubt aware of what Mr. Chamberlain has been doing himself with regard to the establishment of a School of Tropical Medicine at the Seamen's Hospital and he considers it a great advantage that Liverpool should be co-operating on similar lines.

If it would interest you I should be very glad to send you particulars of the Colonial Office scheme and information as to what has been done already but I daresay that you have learnt all that is essential from the newspapers.

Yours very faithfully,
}

Imagine the effect of this reply on the committee. A deputation led by Mr. Jones saw Chamberlain in London and put the case for the Liverpool School. The Colonial Office regretted that no financial aid was possible, but preference would be given in 


\section{B. G. Maegraith}

future to candidates who had attended training programmes in Liverpool. Nevertheless, all doctors appointed to the Colonial Service must attend the school in Albert Dock for at least two months. This was poor commons for Liverpool and in the following month Lord Lister himself was approached and agreed to try personally to persuade Chamberlain to change the latter regulation. The outcome was a further letter, dated November 1899, in which Chamberlain officially confirmed the start of the London School and once again insisted that all Colonial Medical Officers must attend the London School before acceptance in Colonial Service. This letter, however, did acknowledge the creation of a School of 'Tropical Diseases' at University College, Liverpool, which 'was excellently equipped for teaching of tropical medicine'. Apparently the Liverpool School was nevertheless still unsuitable for doctors joining the Colonial Service since the letter continued: 'I propose that Officers already in the Colonial Service should be allowed to receive their instruction in Liverpool instead of at the School in London, but newly appointed Officers will always be sent to the latter School'.

Liverpool did not accept this compromise and continued its pressure for full recognition. At last, on 12 July 1900 the Colonial Office finally capitulated and the school was placed on the same terms as London with regard to newly appointed Officers. Similar recognition was given by the Foreign Office, which was responsible for the Protectorates. Thus, although the Liverpool School came into active being six months before the school in London, it took another year to persuade the Colonial Office to recognise it officially. In such things this is, perhaps, a short time but this early experience in Liverpool serves to remind those of us who work in the provinces that, in terms of central administration, the distance from London to Liverpool is twice the distance from Liverpool to London.

While the struggle for recognition was going on the school itself was developing rapidly. In December 1898 a second committee was formed, calling itself the General Management Committee. Alfred Jones was in the Chair and other members included the Principal and representatives of the Senate and Council of University College, and representatives of merchants, shipowners, steamship owners, sailing ship owners and the Chamber of Commerce. This committee, which is very similar in structure to the present Council, represented a good balance between the commercial life of the City and the University. Since then, the school has always had a prominent member of the Liverpool commercial or industrial world as its Chairman. This has made the school very much part of Liverpool life as the list of chairmen shows. Apart from Alfred Jones, later Sir Alfred, it includes the first Lord Leverhulme, the second Lord Leverhulme, Sir Francis Danson, Sir Frederick Baring, Sir John Hobhouse and more recently Sir Geoffrey Bates. The present Chairman is Mr. Peter Naylor. Contact with the University has continued throughout. Since the University College received its charter as a University in July 1903, the Vice-Chancellor has been an ex-officio member of the Council and representatives of both Senate and Council have served on it.

The major task of the Committee of 1899 was to house the new school and to find the staff to run it. There is no time here to describe the gradual transition of premises from the Thompson Ward of the Royal Southern Hospital and a few back 


\section{History of the Liverpool School of Tropical Medicine}

rooms in the Thompson-Yates laboratory to the Johnston laboratories in University College and eventually to the present premises in Pembroke Place and the Royal Infirmary.

In accord with the modern international status of the school the most recent extension was opened in 1965 by the Director General of the World Health Organisation.

It is more rewarding at this point to confine ourselves to the staff, who so successfully developed the policy laid down in the 'Objectives of the School' published in 1900 as the first Prospectus. These are worth quoting: ' 1 . To train men in the special subject of tropical diseases [women were admitted the following year]. 2. To promote research on tropical diseases. 3. To organize preventive measures in the tropics against disease.' It is interesting to note that the Prospectus overlooked the clinical care of patients which was, of course, one of the initial reasons for the formation of the tropical school in Liverpool.

It was decided that there should be two salaried staff elected; a lecturer in tropical diseases and a demonstrator in tropical pathology. The staff would also include the surgeons and physicians of the hospital, a situation which has long ceased to exist.

In 1899 Boyce was appointed Dean and the Committee faced up to 'the possibility of a gentleman being appointed to this post' (lecturer in Tropical Medicine) 'who is not a member of the staff of the hospital'. Dr. Annett the demonstrator in tropical pathology was elected first, through the influence of Boyce as Professor of Pathology. He was appointed in February 1899 and was thus the first salaried staff member of the school. Annett died only recently at the age of over eighty. Unfortunately, he has not left any memoirs behind him.

The post of Lecturer in Tropical Diseases was advertised and in April 1899 Major Ronald Ross, late I.M.S., was appointed at the full salary of $£ 250$ per annum, subject to the approval of the hospital, which was given in May. It was reported that the committee meeting at which this election was made was long and anxious and that the decision was not reached lightly. (One wonders if there was a possible 'gentleman' already on the hospital staff.) Boyce had subsequently to make a long statement to the management committee regarding the qualifications of Ross before the appointment was confirmed. In this respect he was just three years ahead of the Nobel Committee which awarded Ross the Prize in December 1902. The school was fortunate indeed to get Ross as the first lecturer and subsequently the first Alfred Jones Professor of Tropical Medicine (1903). He had completed his great work on malaria before coming to the school but his activity and enthusiasm were unabated and within three months of election he began the long research into malaria for which the school has now for many years been famous. In July 1899, three months after his election he took the school's first expedition to the tropics, in this case to Sierra Leone on the West Africa coast. This was to remain for nearly fifty years the primary focus of the school's interest in Africa, an interest which has continued to this day. With Ross went Annett and Austin, the famous entomologist from the British Museum.

No financial help was offered for the expedition by the Colonial Office or the Foreign Office, nor, much to Ross's disgust, by the India Office. The school footed the 


\section{B. G. Maegraith}

bill with the help of a cheque of $£ 100$ from the British Medical Association. I must say I have a fellow feeling for Ross who seemed to have managed to raise the money for most of these expeditions. He was clearly spending the same proportion of his time begging money as I have to do with mine.

On 19 August 1899, Ross sent the school his famous cable saying that the expedition had discovered 'the malarial mosquito'. In subsequent letters and later, on return to Liverpool, he regarded this discovery as the overture to eradication of malaria by the control of the mosquito vector. He was very sure of this, but we are still waiting for it. He was not to know the biological hazards of insecticide resistance in Anopheline mosquitoes or of drug resistance in malaria parasites. He was sure that malaria could be eliminated by vector control and he spent much of his remaining time in Liverpool trying to achieve this objective, principally on the West Coast of Africa.

A second expedition was sent to West Africa in 1899, this time to the Gold Coast and the town of Lagos. In this way a pattern was set which continued to the beginning of World War I, during which a total of thirty-two expeditions were mounted. This was the great naturalist observational period of tropical medicine. Every visit to the tropics was richly rewarding and added something to the growing knowledge of the basic epidemiology and aetiology of the local communicable diseases which were ravaging the indigenous people and the visitors and colonists alike. Although this period has now finished in many of the parts of the developing world, it has not entirely gone. In the Far East, for instance, the local natural history of some of the diseases holding back the populations is still as uncertain as it was at the turn of the century.

The diseases which were of great concern in Africa were in particular malaria, sleeping sickness and relapsing fever. All received attention from the staff in the school expeditions. As the expeditions went on, biological material began rapidly to collect in Liverpool and, as the parasites and the vectors became recognized in the tropics, living material was brought home to Liverpool for work in laboratories here. This extension to laboratory work in Britain was a natural development of the field work and steadily came to occupy more and more time. Before long extra working space was needed and a small laboratory was established in 1906 in two cottages in Runcorn, Cheshire. Here many members of the future staff were trained, including Warrington Yorke and Blacklock.

It seems to be generally admitted that Ross was not always an easy person to deal with. Certainly, on occasion he let it be known that he felt he was being underpaid and under-rated. Headings in the School Reports indicate this. Thus, in 1903: 'Resignation of Major Ross. Major Ross has accepted a post in the Jenner Institute in London.' He apparently gave no more than a few days warning before his departure. Three months later:

'Re-appointment of Major Ross.' This time he was appointed to the Walter Myers Lectureship at $£ 500$ a year, $£ 200$ a year more than he had been getting when he resigned, and was given the promise of a Chair in University College, later in the University. The Chair he took over late in 1903 was the Alfred Jones Chair of Tropical Medicine of which I am the fourth holder. Ross retired in 1912 and was given a 


\section{History of the Liverpool School of Tropical Medicine}

lectureship at $£ 400$ a year for five years and an unendowed Chair of Tropical Sanitation. His acceptance of this title illustrates his deep interest in the problems of disease control.

In March 1900 the third expedition went to Nigeria and with it sailed Annett and J. Everett Dutton, the Holt Fellow in Pathology in the University College, a protégé of Boyce. In April a cable came from Lagos announcing the finding of malaria infected Anopheles mosquitoes. Dutton proceeded to the Gambia in September 1901 and early in 1902 he had made a great discovery-the identification for the first time of a trypanosome in the blood of man. The trypanosome was later demonstrated by Castellani in the cerebrospinal fluid and subsequently proved to be the cause of sleeping sickness. It is now described as Trypanosoma gambiense, Dutton, 1902.

Dutton and Todd made up the tenth expedition which went to Gambia and to Senegal in September 1902. A year later these workers went on to Congo Free State and Wolferstan Thomas was appointed to the school's staff to carry on in the Johnston Laboratories the work on trypanosomiasis which had developed from material collected in the Gambia and Senegal in the previous year. Towards the end of 1904 Dutton and Todd had reached Stanley Falls and had demonstrated the cause of tick relapsing fever in man, a discovery which had been made also a few weeks before by Ross and Milne in Uganda. Dutton and Todd transferred the infection from man to monkeys via a vector tick, thus completing the biological cycle. Both contracted relapsing fever. Dutton died. He was only twenty-nine. The cause of tick relapsing fever has been named after him: Borrelia duttoni. (In 1952 a stained glass window was dedicated to Dutton and his parents in the parish church of St. Boniface, Bunbury, Cheshire.)

In April 1911 Newstead, elected in 1905 as Lecturer in Economic Entomology and Parasitology, was made the first Dutton Memorial Professor of Entomology. Newstead was a remarkable man. He was an amateur entomologist with no academic qualifications and was in charge of the Cheshire Museum when he was elected to the school staff. He finally achieved the Fellowship of the Royal Society.

One of the school's major interests at the time was yellow fever and the study of this disease led in June 1900 to the fourth expedition which was despatched to the Amazon. This consisted of Durham and Walter Myers. On the way to the Amazon they visited the yellow fever commission of the United States Government in Cuba in July 1900 and also Washington. There they met and had talks with Finlay, the originator of the idea that Aedes might transmit the disease, Lazear, who subsequently died of yellow fever, and Walter Reed, the man who finally broke the yellow fever story. This must have been an important meeting, in view of the subsequent events in Cuba which led to the final proof that yellow fever was transmitted by Aedes aegypti. Unfortunately, no records of it can be traced. In January 1901 a telegram came from Para (now Belem,) announcing the death of Walter Myers from yellow fever. Durham was infected but recovered and remained for the rest of the year working on yellow fever.

A permanent Lectureship (subsequently a Professorship in Parasitology) and a five-year Fellowship were created to commemorate Myers. At the time, Ross was elected to the Lectureship and Dutton to the Fellowship. 


\section{B. G. Maegraith}

In April 1905 the fifteenth expedition comprising Wolferstan Thomas and Anton Breinl was despatched to the Amazon to study yellow fever. From then on, interest in yellow fever persisted; Boyce went to West Africa in June 1909 on the twentieth expedition to study the disease in Sierra Leone and the Gold Coast, where Davey later worked on the first vaccines. A Yellow Fever Bureau was created in 1911 and expeditions were subsequently sent to Yucatan and to Panama. The fifteenth expedition reached Manaus where Wolferstan Thomas founded a Research Laboratory; this was finally disbanded at his death in 1931. In Manaus, Wolferstan Thomas established a reputation as a humanitarian which has since been recognized by the dedication of a memorial hospital. The full cycle was repeated in 1971 when the present Professor of Parasitology visited Manaus and the old laboratory on a tour of Brazil which we hope will re-establish the contacts with that country that were made so long ago.

The 1914-18 war brought great changes to the school. During the war the new laboratories in Pembroke Place, completed in 1913, were used as a hospital for tropical diseases. At the end of the war the situation changed completely. Expeditions ceased. They were too expensive and the work now required a different approach. This was illustrated by the opening of the Alfred Jones Research Laboratory in Freetown, Sierra Leone. Like the outstation in Manaus, this laboratory represented a new method of attack on endemic disease, namely, continuous research into diseases of a given locality at their place of origin. It was expected that this would lead to results as important as those achieved by the scientific expeditions of the past.

For the next twenty years the staff of the Alfred Jones Laboratory, who were also members of the Liverpool School, carried out high grade research into the diseases of West Africa. The most remarkable achievement was Blacklock's demonstration of the transmission of onchocerciasis (the blinding filarial worm) by the well-named black biting fly Simulium damnosum. This was a discovery of major importance upon which the whole of the modern control of the infection depends. During the second World War the laboratory was used as a parasitological diagnostic centre by the Government of Sierra Leone and by the British West African Army Command.

In this period the school also made notable contributions to the study of tropical medicine. Stephens, working in Liverpool, identified the fourth human malaria parasite Plasmodium ovale, and Warrington Yorke began the research which founded the modern approach to rational chemotherapy of tropical parasitic diseases. Yorke's greatest achievements were the development of diamidino compounds for the treatment of leishmaniasis and the discovery of a method for growing trypanosomes in culture for use as a chemotherapeutic model. This was followed during World War II by the development by the school clinical staff in collaboration with Imperial Chemical Industries, of the new antimalarial drug Paludrine, based on the demonstration, by a future member of the school staff in Freetown in 1940, of the activity of the sulphonamide drug M. \& B. 693 against the falciparum malaria parasite. The death of Yorke in 1943 signalled the end of an era. For a time chemotherapy as such was concentrated in a department named after him, but within a few years this was absorbed into Tropical Medicine.

The chemotherapy of tropical disease has, of course, remained a major interest in 


\section{History of the Liverpool School of Tropical Medicine}

the school, ranging from the treatment of leprosy to the basic factors involved in parasite resistance to drugs. Today, however, it no longer dominates the school's research programmes but takes its place with other fields of interest developed in line with the change in school policy after World War II. This change was most notable in the approach to the tropical developing world. Expeditions had become a casualty of the first World War. In the inter-war years the school spent its energies in consolidating laboratory work largely based on material obtained in the early expeditions and in developing the laboratory in Freetown, Sierra Leone, on the principle that the most productive approach was to study disease in depth in a circumscribed area of the tropics. After World War II it became clear that concentration of effort in one area of the tropics would be unrewarding in an internationally minded world bent on expansion. It was therefore decided that the Freetown laboratory should be abandoned. As a place in the sun it had been valuable and very productive, as the elucidation of the transmission of onchocerciasis testifies, but in the post-war years the school needed more than this. It had to find its place in the developing world and this was achieved by collaboration with the national governments and international agencies such as the World Health Organization, which began to operate in the newly emerging countries. To carry out this new policy the school adopted the philosophy that 'Our impact on the tropics must be in the tropics'. This is still its guiding principle.

In the years following World War II there developed a strong feeling in Europe and North America that the schools of tropical medicine had passed their peak of usefulness and would become redundant. This depressing view was based on the then large numbers of doctors who had had some wartime contact with tropical medicine and on the obvious improvement in medical facilities in some of the developing countries. It also took into account the growing interest in local health problems and in medical training at both undergraduate and graduate level. It was expected that such developments would effectively reduce the burden on the developed world and so on the existing tropical schools. This prediction has proved completely wrong. In fact, the reverse has happened. The schools in Europe and America have proved to be a vital factor in the development of the medical services in the tropical world, and have never had such pressure put upon them. There were many reasons for this. Probably the most important was the mutual realization of the enormous magnitude of the health problems facing the developing countries in their expanding socioeconomic progress and of the chronic shortage of medical and auxiliary personnel capable of dealing with them. Moreover, there is still an incredible lack of real knowledge of the local natural history of many of the endemic bacterial and parasitic infections, information which is essential for the design of control measures, often already hampered by unsolved problems of vector resistance to insecticides, or of parasite resistance to drugs.

It was found that the desperately acute shortage of medical personnel in the tropics could not be met for many years to come by the development of local training centres either at undergraduate or graduate level. There is an urgent need in the developing countries for the skills which come only from experience and scientific training at a high level and it is here, perhaps more than anywhere else, that the real value of the tropical schools has become most apparent. The role of the schools in this respect is 


\section{B. G. Maegraith}

both advisory and practical. It is to the advantage of both the developed and the developing world that centres should be available in the former with staff who can advise and help in the medical planning and operations of the developing countries and who can, at home or abroad, train the people needed for the work on the spot. Such training has become one of the essential functions of the tropical schools in the developed countries. Associated with this responsibility is the whole area of advice in medical developments, from the problems of taking medical care to the periphery to those of socio-economic developments, such as dams and roads, and of population growth. To be able to function in these areas, the schools must above all provide the experienced people needed, and to obtain these and keep them available for helping in the developing world has become a key problem in the developed countries themselves.

The developing countries are well aware of the services the more sophisticated countries can offer them and the need for these services is steadily growing. This in itself is increasing the demands on the tropical schools and other similar resources. The existing schools in Europe and elsewhere in the developing world are also increasing in importance within their own countries. This is because of the steadily growing threat of disease imported by travellers and immigrants. In the past travellers reaching Europe from the warmer parts of the world came by ship and the voyage was usually longer than the incubation period of most major communicable diseases. By the time the traveller reached port, the disease was usually overt and could be easily identified and dealt with. It was thus possible to erect a strong public health barrier which kept out or controlled most exotic diseases. This has all changed in the last two decades, since the aeroplane, and particularly the jet, has taken over world passenger transport from the ship. Among the $\mathbf{4 0 0}$ million passengers who will move through the major airports this year there will be some infected with disease acquired abroad, sometimes unfamiliar to the doctors in Europe. Some passengers already show signs of a disease which can be recognized when they arrive in the airport but others, because of the speed of transport, enter during the incubation period and pass the health barriers looking and feeling well, only to become ill later and present even more difficulty in detection. Travellers of this sort, often natives returning to their own countries, are commonly bringing in acute infections which, because the profession is unaware of them, may be missed, sometimes with disastrous results to the individual or to the community or both. Immigrants tend to arrive with more chronic illnesses, the most dangerous of which is pulmonary tuberculosis and the most dramatic, leprosy.

The value of having schools of tropical medicine in Europe has been amply demonstrated over the last twenty years in respect of imported disease, because, apart from providing centres for proper treatment it has been largely through the schools that the governments and the public have been made so much more aware (but still not aware enough) of the dangers of disease imported in this manner and the need for national surveillance to control the menace. The Liverpool School can claim to have pioneered this. In both developed and developing countries there is very clearly a place for tropical institutes in the modern world for providing service and offering the resources of their knowledge acquired over long experience in tropical 


\section{History of the Liverpool School of Tropical Medicine}

disease. I have made out part of the case for the maintenance of such centres in the developed world. There is an equally good case for having them in the developing countries, and I have no doubt that as time goes on, more will appear there, on the lines of the Faculty in Bangkok, with benefit to the home country and no detriment to the centres already in existence. When the School of Tropical Medicine was founded in Calcutta in 1923, it was said that this was the beginning of the end for the tropical schools in Britain. The truth is that this excellent school has had no effect at all on the British schools, either in reducing the load on them or in diminishing the intake of students. Neither had the Faculty in Bangkok or the many institutes of public health which have arisen elsewhere.

Obviously there are not nearly enough centres in the whole world, let alone in the developing countries, capable of dealing with the immense health problems and the teaching of the experts and teachers required to solve them. This is well recognised in the developing countries themselves since the pressure on European schools is now greater than ever, for training doctors destined to work in the tropics, for fundamental research and for advice and help in dealing with endemic disease and other health problems.

I think we have now answered the second question. Has a School of Tropical Medicine in Europe a place in the modern world? The answer is a resounding Yes, but only if the institute concerned is adaptable enough to fit into the modern changing scene. Let me illustrate this in a little more detail by describing some of the developments in the Liverpool School over the last quarter century.

The reason for teaching Tropical Medicine in the school has changed somewhat over the years. The original intention was to train doctors destined for the tropics particularly for the British Colonies. The early classes were thus almost exclusively British. Today the school is involved in training doctors who have come from abroad, mostly from the independent states which have derived from the colonial empires. Relatively few modern students are British. Some come from Europe and Scandinavia, occasionally from the Americas or Canada. Most of the overseas students are sponsored by their governments and are intended for the local health services. Some are missionaries, servicemen or people who intend to spend their lives in the tropics.

The original course for the Diploma in Tropical Medicine (now in Tropical Medicine and Hygiene) was intended to provide future colonial service doctors with a comprehensive account of the diseases of the relevant tropics and their control. It was found necessary to do this, as you will recollect, because the British medical curriculum of the day did not provide such information, so that British doctors were going to the colonies without adequate training. The objective of the modern much shorter and more condensed course for the combined Diploma is still, in a sense, the same. We are also attempting to provide information which is not included in the medical undergraduate curriculum, but this time we are not concerned with the British curriculum (which is at any rate changing to include 'imported' tropical diseases) but with the teaching programmes in the tropics themselves, since these are often unbelievably inadequate in this respect. The primary objective of the diploma course is to fill up the gaps in the medical curriculum commonly taught in the tropics, which is all too often a simple copy of some European or American curriculum, 


\section{B. G. Maegraith}

containing little or no training in endemic medicine, environmental disease and in community health. It is hoped that one day a more relevant curriculum will be taught more widely in the developing countries. Until that happens, the kind of course we are giving in the school will continue to be helpful to doctors native or expatriate who intend to work in a developing country but have been trained in a 'basic' curriculum. That they themselves realize this is reflected in the great number of applicants for the relatively few (130) places we can offer.

It is interesting to note here that only the last decade there has been a decline in the number of students attending the D.T.M. \& H. classes coming from countries, such as Nigeria and Ghana, where the school has been particularly active and where a more balanced community-oriented curriculum is now being taught. Presumably, in these areas a gap-filling D.T.M. \& H. course is no longer regarded as necessary for the locally-taught graduate. However, the number of such graduates being produced is much too small and the Liverpool D.T.M. \& H. still clearly has something to offer Nigerian or Ghanaian doctors trained abroad and on their way back to their own country. Eventually, when the local medical curricula have been adjusted to cover endemic disease and community health as well as the needs of 'basic' medicine, and when local training can provide adequate numbers of doctors the current D.T.M. \& $\mathrm{H}$. course will have outlived its usefulness as a 'gap-filler' and can be replaced by one designed more for specialists.

In Liverpool we appreciate that 'tropical' specialists are also required in the developing countries, and that there must be some facilities in the developed countries for training them. We have not tried as yet to teach specialists except in paediatrics and experimental science because, with our limited staff and facilities, we have had to decide our own priorities and we believe that the current need is primarily for well-equipped general duty doctors. Training of specialists is more extensively undertaken in some other Schools of Tropical Medicine, but the output is grossly inadequate, even with all organizations working to full capacity. This is a further illustration of the inadequacy of the existing facilities in Europe-and the same applies to America. The pressure on training at all levels is gradually being reduced by the creation of specialized schools in the developing countries but these are very few and are limited in capacity and commonly rely on support from the developed world in manpower especially.

Developing countries are almost invariably very short of doctors and are seldom able to produce adequate numbers for themselves. They thus have to rely largely on expatriate graduates who for the most part have been trained on a 'basic' curriculum in Europe, America or elsewhere, in which scant attention has been given to endemic parasitic disease or to community health. Experience ultimately turns the expatriate doctor into a useful practitioner in the tropics but this takes a long time. The education of the expatriate is therefore a matter of considerable importance to the country concerned. In 1958 this was the case in Ghana which had no medical school and relied entirely on doctors trained abroad, some Ghanaian but mostly expatriate. I pointed this out to President Nkrumah who agreed to the creation of a Ghanaian Institute for Tropical Medicine (subsequently the National Institute of Health) which would be concerned amongst other things with training doctors in local 


\section{History of the Liverpool School of Tropical Medicine}

communicable diseases and in the local problems of general medicine, surgery and obstetrics with the intention of orienting them to public and community health. This course of training was meant merely as an introduction to local problems but it was anticipated that it could very much reduce the time needed for a foreign-trained doctor to adjust to working in Ghana. It was hoped that the Institute would also function as a training ground for future Ghanaian staff of the proposed national medical school since, by involving them in the teaching of a graduate course designed to deal with local problems, they would learn the arts of teaching and determine what local concepts should be taught to the future medical students. For various reasons unconnected with the basic philosophy of the Institute, which was initially a joint project between the Ghana Government and the Liverpool School, this plan was somewhat frustrated. It nevertheless played a part in the development of the now flourishing medical school in Accra, which teaches an undergraduate curriculum adequately concerned in endemic disease and community medicine and health.

The most successful of the school's collaborative programmes since the war has been the development of the Faculty of Tropical Medicine in Bangkok, Thailand. This was established by the Prime Minister, Field Marshal Srisdi Dhanarajata, in 1959. Professor Chamlong Harinasuta, a former student at the Liverpool School was appointed Dean and I became adviser and consultant. The Faculty is now the most distinguished centre of its kind in Southeast Asia. The Liverpool School has been involved in this project since its beginning but the Faculty has always been and has always been seen to be a Thai development, created and financed by the Thai government and staffed by Thais. In this respect we believe it is an example of the proper relationship between the developed and the developing worlds, with a minimum of outside advice and personnel provided by the former and the operative organization and staff by the latter. The continuing close association between the Faculty and the United Kingdom through the Liverpool School has always been a matter of personal relationships and mutual understanding between the two Deans. At no time has there been any official contract between Liverpool and Bangkok. Nevertheless, the arrangement has most of the advantages of an official link and has avoided many of the disadvantages of 'adoption' on the grand scale. Moreover, it has left the expatriate individuals concerned free for other work. Expertise acquired by consultants in one part of the developing world is invariably in great demand in other parts and in this way, a relatively small group of people, such as the staff of the Liverpool School, can cover a very wide area of operations. The objectives of the Bangkok Faculty are roughly the same as those of the Liverpool School, that is to teach a graduate course which would fill up the gaps in the undergraduate curriculum in regard to local endemic disease and community medicine and to carry out research and clinical practice in these fields. It was always hoped that one day the Bangkok project would extend beyond the national boundaries into the region. In 1966, this occurred. I was invited to act as Chairman to a Task Force organized by the Southeast Asian Ministers of Education Secretariat (SEAMES) and in this capacity, with Asian and American colleagues, visited the countries bordering on the South China Sea which might be interested in collaborating in graduate medical training programmes and in research into the local endemic diseases which were depressing living standards in the region. 


\section{B. G. Maegraith}

The Task Force ultimately proposed a scheme (The Tropical Medicine and Public Health (TROPMED) Project) which at the time involved four countries, Thailand, Malaysia, Indonesia and the Philippines. A Central Co-ordinating Board was set up in Bangkok and National Centres for Tropical Medicine were established in each member state. In Thailand the Faculty became the National Centre and the Dean was appointed Secretary General of the Board. The objectives were to establish regional graduate training centres and to co-operate on research on vital regional medical problems. The scheme has been very successful. By 1970 Laos, Vietnam and Singapore had also joined, and I have just returned from Phnom Penh where the Government of the Khmer Republic has agreed to become a full member. Thus, all eight countries of the region, representing something like 250 million people, are now involved in the TROPMED Project. Major graduate teaching centres have been opened in five countries and two more will be developed over the next three years. Each member country sends fellows to these centres for training in subjects varying from Tropical Medicine in Bangkok to Applied Nutrition in Djakarta. This graduate teaching programme is bound to have a great effect on the cultural and medical development of the region. Amongst other things, it is already cutting the loss of local doctors going to Europe and America and not returning. It is also improving the standard of graduate training in the region and is helping to orient the medical approach to community as well as to individual health and so can be expected to improve the standards of government service offered in rural areas, towns and cities.

In this exciting regional development the Liverpool School has played a continuing and significant part by providing the services of its Dean as consultant to both the Bangkok Faculty and the SEAMES project and by secondment of teachers and scientists to member countries. This is very much in line with the school's modern philosophy of providing, at home and for export abroad to the developing countries, the 'capital of knowledge' (as Sir Geoffrey Bates calls it) possessed by the staff. The project illustrates, moreover, the change that has taken place in the last twenty years in the attitude of the tropical doctor, who now has to concern himself in practically all aspects of life in the developing world. The physician is no longer just a medical practitioner. At times he has to be doctor, sociologist, anthropologist and intimately involved in local economic developments in so far as they concern the population and its general health. This multidisciplinary approach is nowhere more important than in the socio-economic developments which have become an almost standard part of the plans of every developing nation.

One of the major postgraduate responsibilities of the developed countries is to teach the future specialists and teachers of the developing countries in general medicine and preclinical subjects. This teaching is carried out by medical faculties and specialist colleges and institutes, many of which constitute centres of excellence where the particular discipline is one of many of equivalent high standard. Such centres are only very slowly being created in the developing world, despite considerable co-operative effort from the developed countries. Graduates from the tropics are therefore looking towards us for training in many subejcts which can often be taught at good technical level already in their own countries. It is thus incumbent on the developed world to 


\section{History of the Liverpool School of Tropical Medicine}

see that appropriate training is available and is designed to meet the real needs of the particular graduate students. In many of the major clinical subjects the courses and teaching facilities already existing in Britain and Europe or in America are immediately suitable for graduates from any area where Western medicine is taught. In some disciplines, however, this is not the case, as the teaching programmes are designed largely to deal with local situations. This is true in Britain in regard to the standard public health training courses and, in many respects, in training in child health.

In 1970, the Liverpool School therefore decided to offer a new type of training in child health which we believed would be suitable for doctors concerned with paediatric problems in the developing countries. A teaching programme was devised which included in-service practice in a children's hospital with instruction in tropical, preventive and community medicine and health. In 1971 a shortened course, taught in the school, was also offered for senior doctors with extensive paediatric experience who were not in need of further hospital training. The intention is to produce welloriented specialists capable of acting as catalysts on return to their own countries and of creating therein centres of excellence in the practice and teaching of child health and in relevant research. The course leads to a Diploma in Tropical Child Health (D.T.C.H.) and is offered as an alternative for the present untidy practice of combining the short Diploma course in child health with the long struggle to obtain a Membership of a Royal College. We believe that the new D.T.C.H. exemplifies the manner in which the school, as a postgraduate institute, can provide practical help for doctors from overseas, at least until they can find the equivalent in their own countries. In this case, the funds have come from the private sector, largely because the present policy in the United Kingdom in regard to funding of university developments, especially at the postgraduate level, makes it extremely difficult to initiate and provide for continuing teaching programmes above the existing establishment, even when technically and morally justified. This parsimonious government policy should be changed, since postgraduate training of doctors from abroad is going to remain the responsibility of the developed world for a long time to come. The pressure will not be lifted until sufficient numbers of adequate teaching centres exist in the tropics. The Schools of Tropical Medicine in Europe and in America are very much involved in helping the developing countries establish medical schools in which doctors can be trained primarily to be good local practitioners. There is nothing new in this, since the principle was inherent in Joseph Chamberlain's original plea for tropical medicine to be taught in the British curriculum at the turn of the century, with the object of producing doctors who could be immediately useful in the colonies.

For many years the Liverpool School has been teaching the elements of clinical tropical medicine in the Liverpool Medical School and is now occupied also in presenting the case for imported disease. It first became involved in undergraduate training in the tropics in 1958 when it created a new form of Lectureship, the so-called Lecturer-at-large, who could be seconded anywhere for up to five years at a time. This was, in a sense, the forerunner of the modern Lecturers (Technical Assistance) now provided by the British Government.

The first lecturer was Dr. (now Professor) Gilles who was seconded to Ibadan, 


\section{B. G. Maegraith}

Western Nigeria, to study a small village (Akufo) with the object of studying the whole life of the people, medical, agricultural, social, family life, population movements etc., thus providing a comprehensive picture of African village life which at the time was entirely missing in Africa. Astonishing as it seems now, this was the first Yoruba village ever examined in this way. We believed it would provide a base line upon which the future teaching of the medical student should be planned, so that the curriculum in the medical school developing in Ibadan would be oriented towards endemic disease and community health. From this idea stemmed the combined operations with the London School and the Rockefeller Foundation working with the University of Ibadan which have given rise to the Ibarapa scheme. Today the Ibadan medical student spends a considerable part of his training in a rural area, learning something about rural medicine and discovering for himself the kind of service the local government is offering to the community. A comparable scheme was subsequently developed in Lagos and the Liverpool School is now collaborating with the Ahmadu Bello University in Zaria, Northern Nigeria, in providing similar teaching for medical students and later, it is hoped, integrated auxiliaries. In all these recent African ventures, the work has largely rested on the shoulders of one or two men. In this way the school staff, small as it is, has made and is making a very considerable impression on developing areas, using very few people.

I believe this is a much better approach than the 'adoption' of a medical school by a university or another medical school in this country. These take-overs have not really been successful anywhere. In the end it is always the individual who counts.

I regret there is no time left to deal with the extensive programmes of research the school is undertaking at home in its highly sophisticated laboratories, and in the field in the many parts of the developing world in which it is working, and I can do no more than mention the advice and consultation we are constantly giving developing countries in many aspects of their medical and socio-economic development. I should, however, point out that the Liverpool School is only one of about twenty in Europe and Western U.S.S.R. and that these institutes are all engaged in somewhat similar projects in the developing world and in their own countries. In 1964 a big step forward in international collaboration was made by bringing the institutes of Europe together under a common Standing Council (of which I am Secretary General) for discussion of mutual problems and interests at home and overseas.

The history of the Liverpool School has been a continuous and logical extension of its original concept from Ross to the present. It is this continuity that makes me believe that its history lies not only in its past, but very much in the present, and the future.

In dealing with these matters in detail and in my recent Heath Clark Lectures in London, I brought them together under the title One World. I think this phrase explains our philosophy and answers both questions: Why in Liverpool? and What are we doing in the modern world? 